\title{
Extra Curricular Life Of Overseas Student-Teachers
}

\author{
Michael W. Firmin, (Email: firmin@cedarville.edu), Cedarville University \\ Ruth L. Firmin, Cedarville University \\ Brenda B. MacKay, Cedarville University
}

\begin{abstract}
Overseas student-teaching is becoming increasingly popular among American college students. Unfortunately, relatively little is known empirically regarding how these students find their experiences-academically or outside of the teaching classroom. Consequently, the present research study used rigorous qualitative methods in order to appraise extra-curricular experiences from a sample of 13 students who completed their student teaching overseas. Results showed students to experience surface relationships with nationals and deeper connections with faculty. While the student teachers reported participating in various excursions alongside nationals, they generally categorized their connections with these people on surface levels, explaining that relationships were hindered by language barrier inhibitions. In contrast, when our participants described their interactions with faculty, they spoke in terms of meaningful connections and bonding experiences.
\end{abstract}

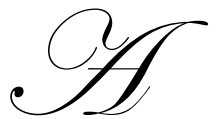

merican college students are becoming more globally focused than ever. McMurtrie (2006) reports that the number of students studying abroad in 2004 rose by 8 percent. In addition to studying abroad, some education majors have the distinct opportunity to participate in the culminating experience of their undergraduate, academic career: student-teaching abroad. Global student-teaching expands the range of student teaching options and offers a unique opportunity for prospective teachers to develop teaching abilities while also expanding their cultural awareness. Such international student-teaching programs are designed for students to live and learn in an environment outside the U.S, being removed from the university campus in both distance and culture. These are distinct programs that broaden the worldview perspectives of student-teachers. Additionally, overseas student teaching provides pre-service teachers with the opportunity to apply learning theories, strategies, and classroom management techniques. Under the direction of a cooperating teacher at the host school, the student-teacher is afforded an opportunity to develop and practice a growing plethora of pedagogical skills and techniques.

International experiences for student-teachers are a growing feature of various university educational programs in the U.S. Research suggests that such options should become more readily available to American students. Baker and Giacchino-Baker (2000) described an international student-teaching project that successfully supported U.S. student growth in the understanding of culture and sharpening of teaching skills needed for working with English learners. They concluded that international student-teaching programs are powerful because of their potential for readying the pre-service teacher to successfully work in a future, multicultural classroom. The benefits from an overseas experience, described by Baker and Giacchino-Baker, are multiplied when student-teachers return from their international experiences to the U.S. and apply what they have learned in the growing American multicultural classroom context.

Responding to global interest and teacher-education professional organizations, Cushner and Brennan (2007) encourage educators to add an overseas student-teaching experience option to the teacher-education curriculum. Their report discusses the immersion of pre-service teachers in a new culture as a cogent means of strengthening intercultural understanding. Recognizing that language limitations can be a significant communication barrier for many students' advancement in some educational milieu, Barkhuizen and Fervok (2006) 
advocate that international student-teaching programs also provide outstanding opportunities for developing language proficiency. Student-teachers who participate in such programs will return to the U.S. better prepared to communicate with non-English speakers and also be better able to engage others unfamiliar sociocultural environments.

Luft (1997) presented results from a pre-service student-teacher's experience, finding three distinct cultural borders in her school community: a student culture, school culture, and a culture of instruction. To most effectively deal with the culture of instruction, the student-teacher clarified her subject matter within the culture in which she was teaching. Acquiring information about the students' background provided her with opportunities to embrace the student culture, which enhanced student-learning. Although the student-teacher initially was uncomfortable in the new school culture, it allowed her to enhance skills needed to work within a diverse environment. As reflective practitioners, Landerholm, Gehrie, and Hao (2004) report that students need to reflect on diversity in ways similar to those indicated by Luft. Two of these domains include cultural differences and teaching styles. As student-teachers better come to grasp the international culture in which they teach, according to Stachowski (2000), they are more ready to value, engage, and empower the school community and the wider community to enhance multicultural efforts.

Clement and Outlaw (2002) view overseas student-teaching as an experience to hone pedagogical skills while developing an understanding of self and diversity. The overseas opportunity affords students occasions to compare pedagogy in the United States and with that used abroad. While students learn about another culture and engage host nationals in everyday life, as aforementioned by Luft (1997) and Landerholm et al.(2004), this experience should translate into a career of more effective classroom teaching throughout the student-teacher's vocational career.

Cultural intelligence has been a useful construct for screening potential overseas student-teachers who will experience a multicultural placement. Brislin, Worthley, and Macnab (2006) report a two-fold meaning of the concept. One is the ability to adapt quickly to new environments. The other refers to sensitivity exercised toward cultural differences, as well as discretion in relation to appropriateness of personal behaviors. Beyond initial screenings, Brislin et al. advocate that supervisors can help students develop in their cultural intelligence, learning new skills and broadening their multicultural worldviews.

McKay and Montgomery (1995) studied the changing perceptions that occurred in student teachers as a result of their placements in overseas schools. These were noted as being twofold: progressive personal growth and increased global awareness. Results showed that the overseas student-teaching experience has the potential to change the student-teacher in several ways, including how the students view themselves, how they view curriculum design and teaching strategies, and increasing classroom diversity awareness. McKay and Montgomery concluded that international student teaching promoted a sense of global awareness, knowledge, understanding, and crosscultural interdependence.

\section{METHOD}

Thirteen participants were selected for involvement in this study. They were students at a selective, private, comprehensive university located in the Midwest United States. All were Caucasian individuals, enrolled in a teacher-education program, pursing public school teaching licensure. During the semester that the study was conducted, these students had just completed their required student-teaching experience - and elected to do so in overseas settings. Demographics of the sample included 12 female and one male student with ages ranging from 2123 years old and all were graduating seniors. The ratio of females to males generally reflected the predominance of females enrolled in the teacher education majors at the university from where the sample was drawn. The 13 individuals represented all of the students who were completing an overseas student-teaching experience that semester and all agree to participate (no attrition). The student-teachers taught in the English language at each of their respective placements. 
Within two days of returning to campus, having completed their overseas student-teaching, we conducted in-depth interviews with all participants. The objective was to assess students' perceptions of their cross-cultural experiences. We used semi-structured interviews since this allowed us to engage all participants with the same initial questions, but also to take the interviews in divergent directions, depending on feedback being received by the participants Seidman, 2006). Thick descriptions (Holliday, 2007) were more readily drawn via this method than using either structured interviews or open interviews. Consequently, sometimes participants took the interviews in directions we initially did not plan, but consistent with standard qualitative methodology, we believe the end result produced very valuable data for our intended purposes.

We used Firmin's (2006) protocol of conducting interview waves. That is, we interviewed all participants once, analyzing the data by coding it and conducting initial thematic analysis. Subsequently, selected participants were interviewed for a second time in order to further explore their responses, clarify issues, and/or acquire elaborations on particular constructs of interest. All interviews were tape recorded and transcribed. Obviously, the names used in this article for reading clarity are pseudonyms.

Maxwell's (2006) open coding protocol was used when conducting data analysis. As such, an inductive method was followed, allowing the themes to emerge from the data. That is, we did not apply deductive strategies, drawing from the existing literature or other sources (ten Have, 2004). Codes were applied from the analysis of the initial interview waves. These were used in order to generate the questions for the second waves of interviews. This enabled us effectively to focus on the main constructs being investigated in the study and focusing on clear themes being communicated by most of the participants in their interviews.

At points, particular constructs were combined or collapsed when overlap warranted doing so. At other times, constructs initially we thought were likely to be themes were discarded due to lack of universal support by the participants. The themes reported in this article were shared by all or most of the participants as they showed principal agreement. Regular meetings among the researchers helped to bolster the internal validity of the study (Silverman, 2006), as we applied independent analysis of the data, showing agreement among us regarding the thematic conclusions.

Internal validity was further enhanced via the use of member checks (Merriam, 2002), i.e., asking various participants to provide feedback regarding the findings. Saturation (Flick, 2002) occurred at the end of our second wave of interviews. That is, repetition continued among the participants, with little new data shared regarding the constructs being studied. In congruence with standard qualitative protocol, we believe this process provided confidence regarding the adequacy of our sample size for this particular qualitative design and study (Guest, Bunce, \& Johnson, 2006).

\section{RESULTS}

From the data set, we previously have presented findings on both the intrinsic and the extrinsic factors that affect student teachers' international experiences (Firmin, MacKay, \& Firmin, 2006; Firmin, MacKay, \& Firmin, 2007). Intrinsic factors included aspects such as cultural differences, fitting-in, and social support, while extrinsic factors encompassed areas such as language adjustment, preparation issues, and distance supervision. Following this research, we explored how the students' extra-curricular lives, which they described on two levels: surface relations with nationals and deeper connections with faculty. While the student teachers reported participating in various excursions alongside nationals, they generally categorized their connections with these people on surface levels, explaining that relationships were hindered by language barrier inhibitions. In contrast, when our participants described their interactions with faculty, they spoke in terms of meaningful connections and bonding experiences. The depth of relationships was the result of two factors. First, the faculty reached out to the student teachers and, second, the student teachers felt they could relate well with the faculty. 


\section{Surface Connections With Nationals}

While overseas, the student teachers capitalized on the opportunity to interact with international people. Most often, the student teachers reported the formation of these connections as they participated in excursions together. The type of activities varied from participant to participant, reflecting the diversity of the countries to which student teachers traveled. However, the emphasis was not on the activity itself, but on the interaction with overseas people. Aileen illustrated this in explaining how she participated in specific activities mainly for the time spent with her international friends: "They [my local roommates] would do stuff, like I would do stuff to hike a mountain with them and I ran a 10K with them..." Students further explained that participating in activities with nationals helped them better to adjust socially. For example, as Belinda fondly recounted planning a road trip with her national friends, she also acknowledged the benefit of surrounding herself with nationals: "I was the only American so I had to fit in." Additionally, Callie described her interactions with nationals, not only as enjoyable, but also as being helpful toward acclimation toward her new environment: "We had, at our house, we had game night every Sunday night, and just getting to know those people who came over for games was fun, and it helped me get socially acquainted with the people there."

Students also viewed excursions with nationals as unique, valuing the opportunities to participate in these international experiences alongside their new acquaintances. Additionally, students found that acknowledging the brevity of their time in a foreign culture further compounded the value of their connections with nationals and their enjoyment of excursions with them. When telling her personal story, Deanna gave this advice regarding excursions:

Try not to turn down opportunities of experience. So, you know, like if they say, "Hey, we're going Nora bogging. We're going to start at 11, we'll probably get home around 3," just make sure your lesson plans get done early, but go for it because you're either going to end up having either a crazy experience, that's going to turn into a hilarious story or it's going to become something wonderful and good memories. But if you turn it down, you may never ever get a second chance.

In sum, students were able to take advantage of activities with nationals, viewing these as key aspects of their overall adjustment as well as providing unique opportunities for social connections. Additionally, students reported finding an apt balance between focusing on their teaching - their reason for being overseas - and yet also not missing once in a lifetime opportunities.

While students valued their interactions with nationals, they also expressed frustration or regret that they were not able to better communicate. Students reported the effects of this language barrier to be multifaceted. For instance, as Eleanor explained, adjustment was required by both the nationals and the student-teachers, as each learned to work around language confusion issues:

I really felt like an outsider the first couple weeks when I hung out with my [new] friends, because they were nervous because they had never had a foreign friend. And I was really nervous because I knew nothing about [their] language, so they would talk with their friends, and I would just sit there by myself the first couple of times. I knew that it would probably be like this the whole night, and I just had to deal with it until they warmed up. Then I realized their English was pretty good, and I could understand and them.

However, for most students, not speaking the foreign language severely hindered the depth of potential relationships with nationals. Meaningful connection requires shared understanding through words. Other expressions, while valuable, were insufficient to provide the perceived depth of personal connection needed. Fern represented most participants when expressing the frustration she experienced as limited communication negatively affected her relationships:

At first, it was one of the most frustrating parts because I didn't know the language and I was living with a Mexican woman. And so a lot of times I felt bad because I couldn't communicate with her as much as I wanted to. I wanted her to know that I was interested in her and I wanted to build a relationship with her, but without really speaking the same language that was really difficult. 
Overall, there was a sense of disappointment as the students realized how drastically language limited their ability to make and develop friendships with the nationals. Overcompensation attempts were not enough to overcome the frustration of unshared thoughts and emotions. Norma recounted her reaction when she realized that language would significantly limit prospective friendships:

I was taking Korean lessons with a Korean teacher, but I wanted to learn faster, and quicker, so I could better communicate with these dear friends of mine. And there were some Koreans that I wanted to get to know, but because of the language barrier, we couldn't even be friends, so that was kind of sad. You couldn't even be friends with someone because of language.

\section{Bonding Connections With Host Faculty}

In contrast, our participants described their interactions with faculty in terms of friendships and meaningful relationships. The depth in relationships developed as a result of two factors. First, the faculty initiated contact with the student-teachers outside of the classroom and specifically reached out to them. Second, the student-teachers felt they could relate well with the faculty on multiple levels, including age similarities and appreciating the faculty's advice. When describing their initial interactions with faculty, student-teachers reported that the role of initiating relationships was filled by the faculty. The participants further added that the faculty went beyond what the studentteachers expected in helping them adjust to their new environments, inside and outside of the classroom. Greta aptly summarized, as she recalled: "The teachers went out of their way to make us feel like we fit in," adding that the faculty's hospitality spread so far as to invite the student teachers into their homes as well as participate in various other activities.

Especially during the first few weeks overseas, as the student teachers were adjusting to new teaching environments and living in foreign cultures, extensions made by the faculty were very meaningful to the student teachers. In fact, many students recalled specific, meaningful accounts from those first few weeks when a faculty member reached out to them. Maisie illustrated this as she recounted:

The third grade teacher that I worked with...she understood where I was coming from. So, she was huge in helping me and any time I needed anything she said, "just come to me." And she would stop me and ask me how my day was, or she would give me a book to help me out or give me ideas for my lessons. So that was huge! She really did an amazing job in just encouraging and just helping.

This personal extension continued beyond professional aid to the student-teachers in the classroom, and developed into helping them learn the ropes outside of school as well. Deanna, for example, recounted how the faculty not only initiated social connections, but also demonstrated an interest in helping the student teachers adjust to their new settings: "I was invited out by a few people and they were like, 'Have you seen downtown yet? Let me show you downtown and I'll try to explain the subway system to you.' All the staff was very open and very helpful." Jack continued to describe how these same teachers later included him in their regular social gatherings, and how these connections became fundamental facets of his social support:

We had one family there who said it's a general habit every week; every Saturday we make pancakes for anyone willing, any who wanted to come join. This is where we live, and the principal lived above us, and he, every Sunday night, would have a really big opening of the TV show that he had on DVD and everybody would bring in food. It would be potluck type thing, just to relax before the week came and, you know, a chance to get together with the teachers and just talk about things.

Additionally, students were sincerely grateful for these connections initiated by the faculty, acknowledging that the interactions initiated by them formed a base from which their relationships developed. Many student teachers, such as Hilary, proposed that their closest emotional bonds were developed with the teachers, or in the words of Ingrid: "I would say that the main social support, friends, that I had were the teachers." Particularly, the student teachers appreciated the faculty's efforts to develop relationships both in and out of the classroom. When 
sharing her story, Ramona described social interactions with a specific faculty member as being highly meaningful, explaining that building these connections outside of the classroom enhanced their working relationship:

My teacher and her husband were great about accepting me, and they really took time to get to know me and to spend time with me. Even outside the classroom. I would go over to their house... and just being involved. They were adopting a Kenyan baby at the time, and keeping up to date with that, and just talking with her was a big deal. So I got to really feel accepted by them as well as it was professional as well. I thought it was a good balance between professional and personal.

The second reason for the bonding with faculty, student-teachers explained, related to their ability in relating with one another. Student-teachers felt that a key factor affording this connection was similarity in age. Norma aptly illustrated the student-teachers' desires to connect socially with cohorts:

There were a number of other teachers that were recently graduates or just a few years older than I was, so I was able to go and hang out with them a lot which was good because like I lived with a...family and, I mean, they're a fairly young family, they have a daughter who was in second grade, and so I could hang out with them. But then it was nice to have someone that was closer to my age.

Similarity in age, of course, may have had multiple implications-including probable shared worldviews, tastes or trend awareness, physical condition or fitness, interests in dating, knowledge of popular music or pop culture, etc. In addition, students such as Greta stressed the important role their cohorts played, helping them to cope emotionally, and suggested that others of similar age best understood the issues with which they were wrestling:

I was very thankful... [I had] really good friends my age at the school. Like the two IT guys were really close to my age...so I had younger people. There were two new first year teaches and all the IT guys were all my age, and if I wouldn't have had them, and the friends they invited me to do stuff with, I would have been really struggling. It was like they were the ones that you have to say what happened today and so you just have to vocalize it and you feel better, and those were the people I did that with, and otherwise I would have been very lonely.

Students further explained that just being around a teacher (in general) often did not evoke the same bonding experience as they felt with teachers who were of a similar age. This does not imply anything negative toward the older teachers, only that there was a greater social attraction to be with the younger ones. Hilary illustrated student teachers' tendencies to connect with faculty on the basis of age:

Well, the teachers, there's a good number that are just out of college or within a few years, so there was one set of apartments that had eight teachers in it, and I would go hang out with them a lot. And, I mean they called it the dorm because it was kind of like a dorm, like they were really close... We would go to movies and we would go over and play games and have dinner and watch TV so that was good. And I definitely grew really close to them...Although I didn't necessarily hang out with any of my cooperating teachers because they were a little bit older, but then I would hang out with some of the younger teachers and had a lot of fun with them.

Because student-teachers generally related well with the faculty, they also tended to rely on them for advice. The counsel student-teachers received from faculty proved to be key information relative to their adjustment in new school and cultural environments. Aileen explained that her friends proved to be paramount sources of key cultural and pedagogical information:

Well, the staff... a couple of the single girls in their twenties, because I knew we'd be similar, and they've been there so they could help me out, not just with the town but with the school. And I became really close with a family, and actually he's the principal of the high school, and his wife was a teacher there, and I would spend every Sunday night with them, and they gave me a lot of guidance in and out of the classroom. 
Often times, students did not initiate relationships for the purpose of gathering counsel, but rather learned from the faculty as a result of time spent together. In this way, mentoring by the experienced teachers in the host country provided important opportunities for them to impact student-teachers' lives. Along with the benefit they provide in classroom settings, this input should not be underestimated when university professors structure overseas experiences for student-teachers. Maisie for example, described a teacher's advice as an added bonus to their friendship:

My cooperating teachers that I worked with in my school, I was able to get to know one of them outside of school as well and spend time with them on the weekend or sometimes after school I would go over to their apartment. And because they were around my age we were able to connect in that way and they were able to answer a lot of my questions about the school or to give me more insight about my students and the culture.

In short, serendipity was a cogent factor relating to student-teacher connections. Although friendships developed (seemingly) for social purposes, secondary benefits were noted by all the participants.

\section{LIMITATIONS AND FUTURE RESEARCH}

The sample used in the present study did not contain minority individuals. The university at which the study was conducted had a minority population of only $6 \%$. Consequently, their simply were not any minority individuals participating in overseas student teaching during the semester that we collected the data for the present study. Future research should focus on the experiences that minority individuals undergo when student-teaching overseas, comparing the results with the current study.

Only one of the 13 individuals in the sample was a male. This reflected, to a large degree, the ratio of female to male students in the teacher education program at the university from which the sample was taken. That is, most students in the teacher education program are women. Consequently, future research should focus on the extra- curricular experiences among male university students. Comparing the findings with the present study should prove to be an interesting comparison and useful for supervising and cooperating teachers.

Generalizing the findings of the present study is a limitation —as is true with all qualitative research — to at least some degree. That is, we are unable to assume that all student-teachers have the same extra-curricular experiences as did the students in our present sample. However, the present findings are valuable as they provide apt bases for future quantitative researchers to use this data in generating hypotheses and survey research questions. In this way, the present study possesses strong heuristic value and will provide a significant foundation for furthering our understanding of overseas student-teachers' experiences.

\section{REFERENCES}

1. Baker, F. J.. \& Giacchino-Baker, R. (2000). Building an international student teaching program: A California/Mexico experience. ERIC reproduction: ED449143, 1-17.

2. Brislin, R., Worthley, R., \& Macnab (2006). Cultural intelligence: Understanding behaviors that serve people's goals. Group \& Organization Management, 31, 40-55.

3. Barkhuizen, G., \& Feryok, A. (2006). Pre-service teachers' perceptions of a short-term international experience programme. Asia-Pacific Journal of Teacher Education, 34, 115-134.

4. Clement, M. C., \& Outlaw, M. E. (2002). Student teaching abroad: Learning about teaching. Kappa Delta Pi Record, 38, 180-183.

5. Cushner, K., \& Brennan, S. (2007). Intercultural student teaching: A bridge to global competence. Blue Ridge Summit, PA: Rowman \& Littlefield.

6. Firmin, M. (2006). Using interview waves in qualitative phenomenological research. In P. Brewer \& M. Firmin (Eds.). Ethnographic \& qualitative research in education. New Castle, UK: Cambridge Scholars Press.

7. Firmin, M., MacKay, B., \& Firmin, R. (In Press). Intrinsic factors affecting overseas student teaching. Education. 
8. $\quad$ Firmin, M., MacKay, B., \& Firmin, R. (In Press). Extrinsic factors affecting overseas student teaching. Journal of Ethnographic \& Qualitative Research.

9. Firmin, M., Warner, S., \& Lowe, A. (2006). Social adjustment among students growing up in foreign mission-field contexts. Christian Higher Education, 5, 115-124.

10. Flick, U. (2002). An introduction to qualitative research $2^{\text {nd }}$ ed. Thousand Oaks, CA: Sage.

11. Guest, G., Bunce, A., Johnson, L. (2006). How many interviews are enough? An experiment with data saturation and variability. Field Methods, 18, 59-82.

12. Holliday, A. (2007). Doing and writing qualitative research. $2^{\text {nd }}$ ed. Thousand Oaks, CA: Sage.

13. Landerholm, E., Gehrie, C., \& Hao, Y. (2004). Educating early childhood teachers for the global world. Early Child Development and Care, 174, 593-606.

14. Luft, J. A. (1997, October). Border crossings: The student teaching experience of a multicultural science enthusiast. Paper presented at the 1997 Arizona K-16 Teaching Reforms Conference, Phoenix, AZ.

15. Maxwell, J. A. (2005). Qualitative research design. $2^{\text {nd }}$ ed. Thousand Oaks, CA: Sage.

16. McKay, J. W., \& Montgomery, J. (1995, April). Changes in perceptions: A comparative study of the experiential learning of international student teachers. Paper presented at the annual meeting of the American Educational Research Association, San Francisco, CA.

17. McMurthie, B. (2006, November). Number of U.S. students abroad rose. Chronicle of Higher Education, 53(13), P. A46.

18. Merram, S. (2002). Assessing and evaluating qualitative research. In S. Merriam (Ed.). Qualitative research in practice. (pp. 18-33). San Francisco: Jossey-Bass.

19. Seidman, I. (2006). Interviewing as qualitative research. $3^{\text {rd }}$ ed. New York: Teachers College Press.

20. Silverman, D. (2006). Interpreting qualitative data. $3^{\text {rd }}$ ed. Thousand Oaks, CA: Sage.

21. Stachowski, L. L. (2000). U.S. student teachers on overseas youth culture: Observations, reflections, and implications for teaching practice. International Education, 30, 5-16.

22. ten Have, P. (2004). Understanding qualitative research and ethnography. Thousand Oaks: CA: Sage. 